\title{
PEACEFUL SETTLEMENT OF DISPUTES: UNITAR'S APPROACH TO THE STUDY OF THE SUBJECT
}

The United Nations Institute for Training and Research (UNITAR) has been engaged, since its establishment, in research and study of a number of problems bearing upon the major objectives of the United Nations, in particular the maintenance of peace and security and the promotion of economic and social development.

Among them, the problem of conflict resolution and of developing an adequate coping mechanism rates as one of the highest priority in terms of relevance to world peace. It is also closely related to the task of ensuring propitious conditions in which peaceful change can take place.

With the advent of nuclear age the character of most conflicts has substantially changed and the tasks confronting the international community in the field of peaceful settlement of disputes are not necessarily identical with those envisaged twenty-five years ago. Conflict has become a multi-dimensional relationship exposed to the influence of a wide range of factors and, in turn, capable of seriously affecting the interests of many states. The notion of legitimate international involvement has expanded to a degree unprecedented in history: it is now recognized that many an internal situation may warrant international concern in view of its outside repercussions.

There is little doubt that the peaceful settlement of disputes will be regarded as one of the central functions of the United Nations in the years to come. Legitimately, several questions arise. Is the mechanism of the United Nations to cope with disputes sufficiently responsive to the needs which arise? Does it live up to the expectations and meet the standards set up by the Charter? How can it be linked more closely with what appear to be new trends in multilateral diplomacy, particularly the reliance on processes of consensus-building and on developing cooperative schemes which can alleviate tensions underlying conflicts? What new, unconventional methods and procedures can be developed in addition to those already firmly established in the armoury of peaceful settlement means? The list of problems could be expanded to include questions regarding legal and institutional developments and the possible contribution of experimental methods developed by the social sciences and other pertinent questions.

One of the characteristic features of the United Nations approach to handling international disputes, as evidenced by the prevailing practice, is an increasing reliance on flexible, often informal, methods of consultation, mediation, conciliation and good offices. These approaches are found in the procedures of the Security Council which, unlike the Council of the League of Nations, has used almost exclusively political, rather than legal, devices. Furthermore, they have been developed and refined by the expanding functions of the Secretary-General whose good offices constitute a very important part of United Nations activities in the field of dispute settlement. There is every reason to believe that these methods will continue to play a significant role in future United Nations endeavours. Perhaps they will become even more relevant as the world progresses towards greater co-operation in the security and disarmament fields, in the solution of outstanding economic and social problems and in the field of environmental control. 
Any endeavour to strengthen the dispute settlement machinery of the United Nations must display a sense of genuine realism. At the same time, however, it should be imaginative and creative in terms of overcoming the present difficulties and limitations.

An increasing awareness of the need to make the United Nations more responsive to the challenges of our times and more powerful in its peacemaking capacities has generated a number of diplomatic initiatives and a considerable interest in the matter on the part of various institutions and scholars. Taking advantage of the occasion of the twenty-fifth anniversary of the United Nations, several Member States have suggested various measures to improve and develop the mechanism and procedures available to the United Nations (see, e. g., Report of the SecretaryGeneral on Consideration of Measures for the Strengthening of International Security, doc. A/7922, 15 May 1970). A number of international conferences and symposia held in the last two years or so have devoted their efforts to the search for new ideas and new opportunities to enlarge the powers and resources of the United Nations in this particular area of its activities.

For its part, UNITAR, as a research arm of the United Nations, is undertaking a study of the most relevant aspects of peaceful settlement of disputes, in particular those which are closely related to the functions of the United Nations organs. The primary purpose of the project is to explore the frontiers of empirical and theoretical knowledge about international conflict and see to what extent solutions are possible, to analyse the potential roles of the relevant procedures and instrumentalities developed within the United Nations and elsewhere, and to ascertain the feasibility of new approaches to the problem of peaceful settlement of disputes. The project, as it stands, is Charter-based and action-oriented. An important goal is to provide new ideas and to convey new knowledge about ways and means of dispute settlement to those who participate in international decisionmaking. At the same time, it is designed to provide a framework for communication between practitioners and scholars, in the hope that if members of these two groups can interact directly they will point to the possibilities open through their pooled experience to express the needs of today's world.

One of the major tasks confronting a researcher dealing with a problem of such complexity is to find a proper focus for his endeavours. Although many partial approaches have been made to the problem of conflict resolution and considerable knowledge about the subject has been accumulated, it can still be said that we are confronted with a relatively new field of inquiry with which it is not easy to deal. It is a subject which not only escapes precise definition but also one which can be approached from widely differing angles. There is both the need for linking research with the practical activities of the United Nations and the requirement to come up with new findings so as to widen the perspectives of future policyplanning, and it may prove desirable to operate on a double level, empirical and experimental. The empirical level will deal with the diplomatic and policy-making experience and spell out the possibilities of perfecting the tools and procedures already at the disposal of the United Nations. On the experimental level, the research will attempt to assess and develop a methodology of influencing the conflict behaviour of States through alterable components such as perception and human communication, and to arouse interest in their application.

The project envisages a series of studies which could be broadly divided into two categories: first, studies dealing with aspects of dispute settlement within the Uni- 
ted Nations framework with special emphasis on meditation, conciliation and good offices and, secondly, studies concerned with social-psychological approaches to conflict resolution. The latter part will provide a testing ground for ideas and methods developed by modern political and social sciences.

The first series of studies undertaken by UNITAR is nearing its completion. They include the studies on the role of environmental factors in mediation; the development of the means of peaceful settlement enumerated in Article 33 of the Charter; settlement of territorial and boundary disputes; the perspectives from which third-party assistance in the settlement of disputes can be viewed; mechanism and rules applied in the process of mediation; procedural devices employed by the Security Council in its decision-making; the methods of fact-finding; and the "good offices" of the Secretary-General. It is envisaged that these and other studies which will have been completed by the end of 1970 will be published in the book form and made available to governments, international organizations and academic institutions throughout the world.

With regard to the social-psychological approaches to conflict resolution, UNITAR is concerned with the extent of possible application of the respective techniques to the conduct of international relations. As it is known, in the past few years research and practical tests have been carried out in various places on the use of sensitivity training and other techniques designed to change perceptions and promote communication as a possible means of alleviating tension and developing conflict solving attitudes among individuals, groups and states. In May 1970 UNITAR convened a workshop on these techniques which was attended by a number of academic experts, diplomats and other persons concerned with actual disputes. The aim of the workshop, which has been fully met, was to obtain advice and assistance in analysing and structuring the results achieved by the use of experimental methods such as controlled communication (see John Burton, Conflict and Communication. London: Macmillan, 1969), T-group approach (see Leonard W. Doob [ed.], Resolving Conflict in Africa: The Fermeda Workshop. New Haven and London: Yale University Press, 1970), and possibly other methods. As a result, UNITAR has prepared a fairly comprehensive paper entitled "Social Psychological Techniques and the Peaceful Settlement of International Disputes: A Report on a Workshop at Lake Mohonk, New York, Mai 1970".

Both areas of study are directed to the same point, that of opening up new lines of inquiry for those who are seeking feasible approaches to the settlement of disputes. The expansion of the frontiers of our knowledge about conflict must be attributed equally to the recorded experience of diplomats and statesmen and to those of the academic world who are gradually establishing an integrated methodology of conflict resolution. The premises and practices of the former are firmly based on the empirical processes of trial and error, whereas the insights of the latter derive from observing international events for indications of what can be explained and what predicted. The benefits accruing from an alliance between the practitioners and the scholars in this field are potentially enormous. Their collaboration could open up a new range of ideas and hel to reinforce the machinery, as well as transforming the methods of settling disputes peacefully. It also provides and appropriate framework within which to carry out UNITAR research.

The project as conceived envisages the use of a multiplicity of settings and techniques, combining individual research with collective inquiry through a system 
of workshops and study groups, which will take advantage of the potential expertise available in different countries, assimilating the contributions of the various disciplines concerned. It is expected that collaboration in the conduct of the study, particularly through workshops and multinational teams, will have an impact on practitioners and the academic community.

The initiating of the project and its carrying out in the present scope has been made possible thanks to the financial support from several non-governmental sources, including a substantive grant from the Volkswagen Foundation in Hanover.

The history of the twentieth century reminds us that there are many ways for nations to be drawn into dangerous situations of turmoil, but fewer ways of checking effectively the rise of conflict and of transforming it into a process of constructive problem-solving. Central to the problem of conflict resolution today is the development of the capabilities of the United Nations so that it may play a more positive role in settling disputes likely to endanger peace and security, disputes which could upset the commonly shared ideals of the international community.

UNITAR is in a uniquely advantageous position to undertake a study of this subject. Being related to the United Nations, it can draw directly upon the experience and structures of the contemporary international community and can feel its basic concernes and needs. Its international position commits the Institute to a position of strict objectivity and a sense of genuine realism. This, in turn, enhances the relevance of the findings of its research and opens the way to their practical application, both within and outside the United Nations. The project on peaceful settlement of disputes certainly does not lack attractiveness for a researcher as well as for the potential consumer. If successful, as UNITAR earnestly hopes, its results could be a meaningful contribution to United Nations endeavours in maintaining peace and security as the Organization enters the second quarter century of its existence.

Dr. Vratislav Pechota 